
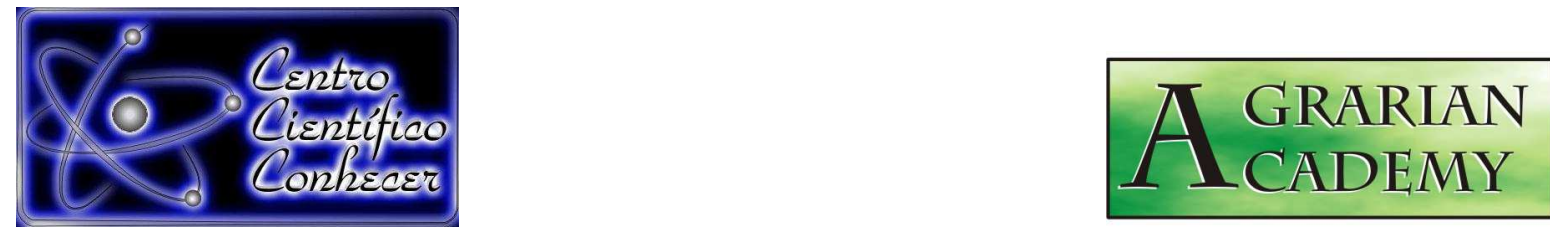

\title{
ANÁLISE DE MUDAS DE MARACUJÁ AMARELO EM FUNÇÃO DO TAMANHO DO RECIPIENTE E DA ADUBAÇÃO COM NPK
}

\author{
Wíctor Állyson Dias Rodrigues ${ }^{1}$, Laudeline Dantas Santana ${ }^{2}$, \\ Antonio Alves Pinto ${ }^{2}$, Laura Leopoldina Sousa ${ }^{2}$, Felipe Thomaz da Camara ${ }^{3}$ \\ 1 Graduando em Engenharia Agronômica da Universidade Federal do Cariri \\ (wictor.allyson@hotmail.com), Crato-Brasil; \\ 2 Graduando em Engenharia Agronômica, Universidade Federal do Cariri; \\ 3 Dr., Prof. Adjunto CCAB, Universidade Federal do Cariri.
}

Recebido em: 30/11/2017 - Aprovado em: 15/12/2017 - Publicado em: 31/12/2017 DOI: 10.18677/Agrarian Academy 2017b6

\begin{abstract}
RESUMO
O Brasil é o maior produtor e consumidor mundial de maracujá amarelo, com produção crescente nos últimos anos, com as práticas no preparo das mudas sendo importante fator para elevar a produtividade. Por isso, o presente estudo teve por objetivo avaliar o desenvolvimento das mudas de maracujá amarelo em função do tamanho do recipiente e das porcentagens de adubo NPK antecipadas que seriam utilizadas no transplantio. O experimento foi conduzido no Centro de Ciências Agrárias e da Biodiversidade da Universidade Federal do Cariri (UFCA), em delineamento inteiramente casualizado, em esquema fatorial e cinco repetições. $O$ primeiro fator foi o tamanho do recipiente plástico $(12 \times 20,14 \times 20$ e $16 \times 25 \mathrm{~cm})$, e o segundo as porcentagens da adubação mineral com NPK antecipadas do transplantio $(0 ; 1 ; 2 ; 3 ; 4$ e $5 \%)$. Melhores resultados foram obtidos para o maior recipiente plástico $(16 \times 25 \mathrm{~cm})$, com a adubação química aos 30 DAS sendo prejudicial em todas as proporções avaliadas.
\end{abstract}

PALAVRAS-CHAVE: composto orgânico, massa verde, raízes, substrato.

\section{ANALYSIS OF YELLOW PASSION FRUIT SEEDLINGS AS A FUNCTION OF CONTAINER SIZE AND FERTILIZATION WITH NPK}

\begin{abstract}
Brazil is the world's largest producer and consumer of yellow passion fruit, with increasing production in recent years, with practices in seedling preparation being an important factor to raise productivity. Therefore, the present study aimed to evaluate the development of yellow passion fruit seedlings as a function of the size of the container and the percentages of anticipated NPK fertilizer that would be used in transplanting. The experiment was conducted in the Center of Agrarian Sciences and Biodiversity of the Federal University of Cariri (UFCA), in a completely randomized design, in a factorial scheme and five replications. The first factor was the size of the AGRARIAN ACADEMY, Centro Científico Conhecer - Goiânia, v.4, n.8; p.59 2017
\end{abstract}


plastic container $(12 \times 20,14 \times 20$ and $16 \times 25 \mathrm{~cm})$, and the second the percentages of mineral fertilization with NPK anticipated from the transplanting $(0 ; 1 ; 2 ; 3 ; 4$ and $5 \%)$. Better results were obtained for the larger plastic container $(16 \times 25 \mathrm{~cm})$, with the chemical fertilization at 30 DAS being harmful in all proportions evaluated.

KEYWORDS: roots, green mass, substrate, organic compound.

\section{INTRODUÇÃO}

O maracujá amarelo é um fruto bastante consumido no Brasil na forma in natura, na forma de sucos e outros subprodutos. Sua produção vem consolidandose como uma boa fonte de renda, em função da elevada procura e bom preço de mercado, além do rápido ciclo produtivo, que quando comparado a outras frutíferas é mais precoce, visto que seu período de colheita inicia-se de 6 a 9 meses após o plantio, dependendo do local do cultivo (SISTEMAS DE PRODUÇÃO EMBRAPA, 2015).

A respeito da produção nacional, apesar de um decréscimo entre os anos 1990-2000 (IBGE, 2013), vem crescendo de forma significativa nos últimos anos, sendo considerado o maior produtor e consumidor mundial de maracujá amarelo, com produção de 614 mil toneladas em uma área de 45.300 ha, destacando-se no agronegócio da produção de frutas e contribuindo para o desenvolvimento do setor agrícola (FAO, 2012). A região Nordeste concentra boa parte da produção nacional com cerca de $64,90 \%$, sendo os estados da Bahia e Ceará os mais produtivos com 297.328 e 93.079 toneladas, respectivamente, no ano de 2015 (IBGE, 2016).

Visando aumentar a produtividade de maracujá, produzir ou adquirir mudas de boa qualidade é um fator que colabora para o melhor desenvolvimento do pomar, fazendo uso de mudas provenientes de sementes de qualidade e que sejam saudáveis e vigorosas, bem estruturadas e resistentes ao transplantio. Mudas mal formadas e desnutridas dificilmente proporcionarão bons pomares, mesmo aplicando alta tecnologia na condução da cultura (SANTOS et al., 2017). Esse fator sozinho não garante que as plantas serão altamente vigorosas e produtivas, mas junto com outros fatores como o manejo da cultura, influi significativamente no resultado final.

Apesar de existir outros modos, os recipientes de polietileno são atualmente os mais utilizados para a produção de mudas, por serem mais acessíveis e de fácil manuseio, apesar das desvantagens como a dificuldade das operações de viveiro, transporte para o campo, distribuição das mudas, em virtude de o substrato utilizado ser muito pesado e com maior frequência do enovelamento do sistema radicular (CHAGAS et al., 2006), contribuindo assim para a má formação das plantas e redução na produtividade.

O tamanho do recipiente para preparar as mudas é de escolha do produtor, tendo em vista que este influencia diversas características da muda e pode impactar o potencial de sobrevivência no campo e a produtividade da cultura (SÁ et al. 2014). Além da escolha do recipiente, a adubação quando aplicada corretamente influencia significativamente na qualidade e produtividade do maracujá, sendo que as quantidades de Nitrogênio, Fósforo e Potássio recomendadas são variáveis (FORTALEZA et al., 2005).

A nutrição de plantas por meio de adubação química é um fator preponderante para o desenvolvimento e aumento da produção conforme Meneghette et al. (2017), logo, o fornecimento adequado e balanceado desses nutrientes é fundamental para favorecer benefícios significativos à produção.

Conforme Miyake et al. (2017) o nitrogênio é um dos nutrientes fundamentais para o desenvolvimento de folhas e ramos, com função estrutural e grande 
responsável pelo crescimento e produção de novas células e tecidos. Depois do nitrogênio, o potássio é o mais requerido durante o desenvolvimento do maracujazeiro, atuando no processo de abertura e fechamento dos estômatos e da síntese de proteínas dos tecidos meristemáticos (CAMPOS et al., 2007), tendo grande influência na produtividade, comprimento e diâmetro dos frutos segundo Fortaleza et al. (2005). Não diferente, o fósforo, apesar de ser pouco absorvido pelo maracujazeiro, é um nutriente importante aos processos de armazenamento e transferência de energia (MIYAKE, 2016), tornando-se fundamental para o crescimento inicial das plantas.

Desta forma, o objetivo do trabalho foi avaliar a qualidade das mudas de maracujá amarelo produzidos em diferentes tamanhos de recipientes para a produção de mudas, submetidos a diferentes porcentagens da adubação mineral com NPK que seria utilizado no transplantio.

\section{MATERIAL E MÉTODOS}

O trabalho foi realizado no período de nove de agosto a seis de novembro de 2016 no Centro de Ciências Agrárias e da Biodiversidade (CCAB) da Universidade Federal do Cariri (UFCA), situada no município de Crato, Ceará, com as coordenadas geográficas $7^{\circ} 14^{\prime} 49^{\prime \prime S}, 39^{\circ} 22^{\prime} 05^{\prime \prime} \mathrm{W}$ e 415 metros de altitude.

O clima da região, segundo Köeppen, é classificado como Aw', considerado tropical úmido, com inverno característico seco, com estação chuvosa presente de novembro a abril e estação seca no inverno de maio a outubro. O clima Aw é encontrado no litoral e serras do Ceará, com precipitações geralmente superiores a $750 \mathrm{~mm}$ anuais (EMBRAPA, 2016).

O delineamento experimental utilizado foi inteiramente casualizado em esquema fatorial $3 \times 6$, constando de cinco repetições. O primeiro fator analisado foi 0

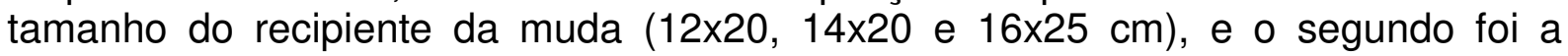
porcentagem da dose recomendada de adubo no transplantio $(0 ; 1 ; 2 ; 3 ; 4$ e $5 \%$.

A semeadura do maracujá amarelo foi realizada no dia nove de agosto de 2016 nos recipientes plásticos de dimensões de acordo com os níveis avaliados. $O$ substrato utilizado foi uma mistura de $50 \%$ de solo do local, de textura arenosa, com $50 \%$ de composto orgânico.

Quando as mudas estavam com 34 Dias Após a Semeadura (DAS) foi realizada a adubação química nos recipientes, ao lado das mudas e incorporados manualmente ao substrato, com as porcentagens de adubo químico referentes ao recomendado para o maracujá amarelo no momento do transplantio, procurando verificar possíveis melhorias no desenvolvimento das mudas, que permaneceram em formação por mais 55 dias, sendo avaliadas aos 89 DAS, no dia seis de novembro de 2016.

A dose recomendada no momento do transplantio do maracujá em fundação, segundo a EMBRAPA (2016), considerando o espaçamento de dois metros entre fileiras e de três metros entre as plantas, foi de $90 \mathrm{~g} \mathrm{planta}^{-1}$ de N $\left(429 \mathrm{~g} \mathrm{planta}^{-1} \mathrm{de}\right.$ Sulfato de Amônio), $72 \mathrm{~g}_{\text {planta }}{ }^{-1}$ de $\mathrm{P}_{2} \mathrm{O}_{5}$ (400 $\mathrm{g}_{\text {planta }}{ }^{-1}$ de Superfosfato Simples) e $12 \mathrm{~g}$ planta $^{-1}$ de $\mathrm{K}_{2} \mathrm{O}$ (20 $\mathrm{g}_{\text {planta }}{ }^{-1}$ de Cloreto de Potássio). Desta forma, as dosagens depositadas nos recipientes, de acordo com os níveis do fator porcentagem da adubação de fundação pode ser visualizada na Tabela 1. 
TABELA 1. Quantidade de nutrientes e adubos simples utilizados por recipiente em função da dose recomendada no transplantio do maracujá amarelo

\begin{tabular}{lllllll} 
Níveis & de & \multicolumn{3}{c}{ Nutrientes $\left(\mathrm{g} \mathrm{planta}^{-1}\right)$} & \multicolumn{3}{c}{ Adubos Simples $\left(\mathrm{g} \mathrm{planta}^{-1}\right)$} \\
\cline { 2 - 7 } & $\mathrm{N}$ & $\mathrm{P}_{2} \mathrm{O}_{5}$ & $\mathrm{~K}_{2} \mathrm{O}$ & $\mathrm{SA}$ & $\mathrm{SS}$ & $\mathrm{KCl}$ \\
\hline $0 \%$ & - & - & - & - & - & - \\
$1 \%$ & 0,90 & 0,72 & 0,12 & 4,29 & 4,00 & 0,20 \\
$2 \%$ & 1,80 & 1,44 & 0,24 & 8,58 & 8,00 & 0,40 \\
$3 \%$ & 2,70 & 2,16 & 0,36 & 12,87 & 12,00 & 0,60 \\
$4 \%$ & 3,60 & 2,88 & 0,48 & 17,16 & 16,00 & 0,80 \\
$5 \%$ & 4,50 & 3,60 & 0,60 & 21,45 & 20,00 & 1,00 \\
\hline
\end{tabular}

$\mathrm{N}$ - Nitrogênio; $\mathrm{P}_{2} \mathrm{O}_{5}$ - Fósforo; $\mathrm{K}_{2} \mathrm{O}$ - Potássio; $\mathrm{SA}$ - Sulfato de Amônio; SS - Superfosfato Simples; $\mathrm{Kcl}$ - Cloreto de Potássio

As variáveis analisadas foram: a altura das plantas (mensurada do substrato até a ponta do ramo principal da planta), o número de folhas, o comprimento da raiz (mensurado com fita métrica), e as massas da raiz, do colmo, das folhas e da planta inteira (obtidos por pesagem em balança semianalítica de precisão para duas casas decimais, em gramas).

Os dados foram tabulados e submetidos à análise de variância e ao teste de comparação de médias de Tukey a $5 \%$ de probabilidade para o fator qualitativo (Tamanho do Recipiente) e os dados quantitativos (Porcentagem de adubação no transplantio) à análise de regressão para escolha do melhor modelo significativo, utilizando-se o programa estatístico SISVAR 5.3 (FERREIRA, 2010).

\section{RESULTADOS E DISCUSSÃO}

Nas tabelas 2 e 3 verificam-se altos coeficientes de variação (cv>30\%), principalmente em decorrência da alta mortalidade de plantas para as doses altas de adubo NPK, em decorrência da salinidade provocada, com algumas repetições ficando sem plantas para expressar os resultados, ocasionando valores altos de $\mathrm{CV} \%$.

Não ocorreu interação significativa entre os fatores Recipiente $(R)$ e Adubação (A) para as variáveis analisadas nas tabelas 2 e 3 . Analisando cada fator individualmente, verifica-se na tabela 2 , que somente a altura foi significativa em relação ao recipiente utilizado, com uma significância de $5 \%$ de probabilidade segundo o teste de Tukey, sendo que os melhores resultados foram do recipiente de maior volume, visto que fornece maior espaço para o desenvolvimento da planta, afetando assim, positivamente a altura, resultados semelhantes aos encontrados por Antoniazzi et al. (2013) que ao investigar a influência de recipientes de diferentes tamanhos e formatos para mudas de Cedrela fissilis Vell., observou a diminuição dos parâmetros de crescimento com a diminuição do tamanho do recipiente. 
TABELA 2. Síntese da análise de variância e do teste de médias, do fator Recipiente, para o número de folhas, comprimento da raiz e altura das plantas de maracujá amarelo

\begin{tabular}{|c|c|c|c|}
\hline \multirow{2}{*}{$\begin{array}{l}\text { Fontes de } \\
\text { Variação }\end{array}$} & \multicolumn{3}{|c|}{ Valores de F } \\
\hline & Altura & Número de Folhas & $\begin{array}{c}\text { Comprimento } \\
\text { Raiz }\end{array}$ \\
\hline Recipiente (R) & 3,16 * & $2,04^{\mathrm{NS}}$ & $2,49^{N S}$ \\
\hline Adubação (A) & 9,82 ** & 7,95 ** & $11,08^{* *}$ \\
\hline$R \times A$ & $1,10^{N S}$ & 0,99 NS & $1,41^{\mathrm{NS}}$ \\
\hline \multirow[t]{2}{*}{ CV\% } & 90,88 & 85,53 & 80,51 \\
\hline & \multicolumn{3}{|c|}{ Teste de Médias de Tukey $(p<0,05)$} \\
\hline \multirow[t]{2}{*}{ Fator } & Altura & Número de Folhas & $\begin{array}{c}\text { Comprimento } \\
\text { Raiz }\end{array}$ \\
\hline & $\mathrm{cm}$ & Unidade & $\mathrm{cm}$ \\
\hline \multicolumn{4}{|l|}{ Recipiente } \\
\hline $12 \times 20$ & $20,7 b$ & $6,2 \mathrm{a}$ & $9,1 \mathrm{a}$ \\
\hline $14 \times 20$ & $32,5 a b$ & $8,5 \mathrm{a}$ & $12,7 \mathrm{a}$ \\
\hline $16 \times 25$ & $38,4 \mathrm{a}$ & $9,2 \mathrm{a}$ & $14,6 \mathrm{a}$ \\
\hline
\end{tabular}

**: significativo $(P<0,01)$; *: significativo $(P<0,05)$; NS: não significativo; $C V \%$ : coeficiente de variação. Médias seguidas pela mesma letra minúscula na coluna, não diferem entre si pelo teste de Tukey a $5 \%$ de probabilidade.

Para o comprimento da raiz, bem como o número de folhas, não foram encontrados resultados significativos em relação ao recipiente utilizado, apesar de serem observados maiores médias para os maiores recipientes. Para o fator Adubação, as três variáveis foram significativas $(p<0,01)$, e ao fazer as análises de regressão, notou-se que com 0 aumento das doses de adubo, foi verificado comportamento linear significativo $(p<0,01)$ para a altura das plantas, comprimento da raiz e número de folhas, com redução nos valores à medida que elevou a dose de adubo (Figura 1).

Esses resultados negativos em relação à altura da planta, número de folhas e comprimento da raiz, se dá devido ao excesso de adubação química que prejudica o desenvolvimento devido aos altos índices de salinidade desses adubos, causando danos principalmente ao sistema radicular, a absorção de água e nutrientes é comprometida, e pode induzir ao aumento da pressão osmótica da solução do solo, prejudicando o desenvolvimento das mudas (WANDERLEY, 2009). Porém, esperavam-se resultados positivos em pequenas doses, fato não observado, evidenciando que o composto orgânico na proporção de $50 \%(\mathrm{v} / \mathrm{v})$ foi suficiente para satisfazer as necessidades nutricionais da cultura aos 89 dias após a semeadura. 


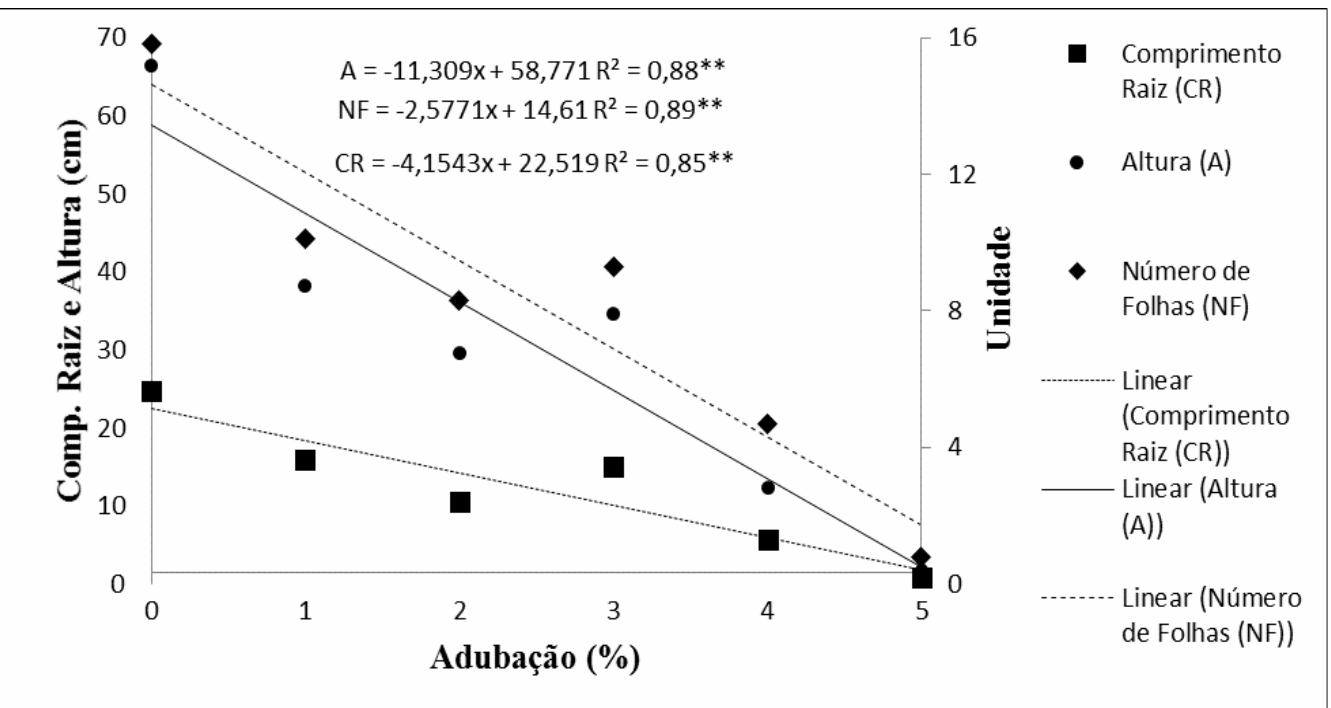

FIGURA 1. Comportamento da altura das plantas, comprimento de raiz e número de folhas de mudas de maracujá amarelo em função da porcentagem de adubo mineral antecipa do transplantio.

$\mathrm{Na}$ tabela 3 houve significância para as três variáveis em relação ao recipiente utilizado, com $1 \%$ de probabilidade para a massa da raiz e massa do colmo, e de $5 \%$ para a massa das folhas, sendo que os melhores resultados foram novamente para os recipientes de maior volume, diferente do encontrado por Antoniazzi et al., (2013) quando a razão de massa de folhas e de raízes não apresentaram diferenças significativas entre as mudas em recipientes grandes e pequenos. Porém dados semelhantes foram encontrados por Chagas et al. (2006) com melhores resultados para os maiores recipientes, independentemente do tempo de permanência da muda, que variou de 40 a 70 DAS.

TABELA 3. Síntese da análise de variância e do teste de médias, do fator Recipiente, para a massa da raiz, do colmo e das folhas por muda de maracujá amarelo

\begin{tabular}{|c|c|c|c|}
\hline \multirow{2}{*}{$\begin{array}{l}\text { Fontes de } \\
\text { Variação }\end{array}$} & \multicolumn{3}{|c|}{ Valores de F } \\
\hline & Massa Raiz & Massa Colmo & Massa Folhas \\
\hline Recipiente (R) & $5,00^{* *}$ & $5,28^{* *}$ & 4,09 * \\
\hline Adubação (A) & $9,74^{* *}$ & $6,93^{* *}$ & 7,31 ** \\
\hline$R \times A$ & $1,35^{\mathrm{NS}}$ & $0,86^{\mathrm{NS}}$ & $0,92^{\mathrm{NS}}$ \\
\hline \multirow[t]{2}{*}{ CV\% } & 99,71 & 103,92 & 95,48 \\
\hline & \multicolumn{3}{|c|}{ Teste de Médias de Tukey $(p<0,05)$} \\
\hline Fator & Massa Raiz & Massa Colmo & Massa Folhas \\
\hline \multirow{2}{*}{\multicolumn{4}{|c|}{ Recipiente }} \\
\hline & & & \\
\hline $12 \times 20$ & $1,0 \mathrm{~b}$ & $2,6 \mathrm{~b}$ & $8,0 \mathrm{~b}$ \\
\hline $14 \times 20$ & $1,8 a b$ & $5,1 a b$ & $12,9 a b$ \\
\hline $16 \times 25$ & $2,4 \mathrm{a}$ & $6,7 \mathrm{a}$ & $16,8 \mathrm{a}$ \\
\hline
\end{tabular}

**: significativo $(P<0,01)$; *: significativo $(P<0,05)$; NS: não significativo; $C V \%$ : coeficiente de variação. Médias seguidas pela mesma letra minúscula na coluna, não diferem entre si pelo teste de Tukey a $5 \%$ de probabilidade. 
Para o fator adubação, todas as variáveis apresentaram modelos lineares significativos $(p<0,01)$, com resultados decrescentes em relação ao aumento das doses de adubo, tendendo ao desenvolvimento mínimo destes (figura 2), novamente influenciados pelo excesso de adubos químicos que impediu o melhor desenvolvimento da planta. $O$ excesso de sais pode afetar a planta de duas formas: através do aumento do potencial osmótico do solo, em que a quantidade de sais no solo e a energia gasta pela planta para absorver água e outros nutrientes é diretamente proporcional; e pela toxidez de alguns elementos, principalmente sódio e cloretos, que em excesso, causam distúrbios fisiológicos nas plantas (BATISTA et. al., 2002). Esses dois fatores são possíveis fatores que influenciaram nos resultados negativos em relação à adubação com NPK.

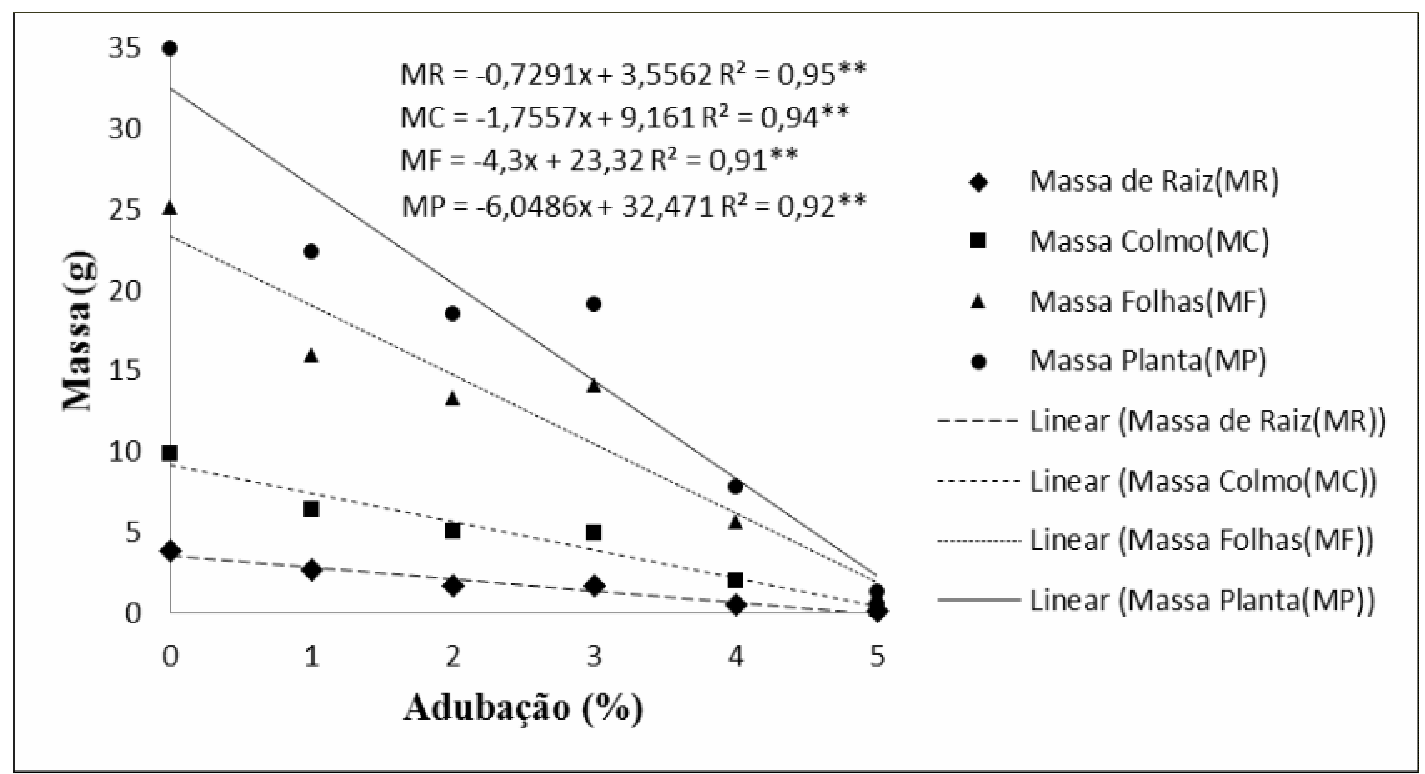

FIGURA 2. Síntese da análise de variância e do teste de médias, do fator Adubação para a massa da raiz, do colmo, das folhas e da planta por muda de maracujá amarelo

\section{CONCLUSÃO}

As mudas de maracujá amarelo podem ser produzidas com melhor eficiência em recipientes de polietileno preto com dimensões de $16 \times 25 \mathrm{~cm}$, não sendo recomendado a adubação no próprio recipiente, já que o substrato utilizado, contendo $50 \%$ de solo do local, de textura arenosa, e $50 \%$ de composto orgânico, é o suficiente para manter a muda até o período de transplantio.

\section{REFERÊNCIAS}

ANTONIAZZI, A. P.; BINOTTO, B.; NEUMANN, G. M.; SAUSEN, T. L. BUDKE, J. C. Eficiência de recipientes no desenvolvimento de mudas de Cedrela fissilis Vell. (Meliaceae). Revista Brasileira de Biociências, Porto Alegre, v.11, n.3, p. 313-317, $2013 . \quad$ Disponível em: <http://www.ufrgs.br/seerbio/ojs/index.php/rbb/article/view/2390>Acesso em 05/nov2016. 
BATISTA, M. J.; NOVAES, F.; SANTOS, D. G.; SUGUINO, H. H. Drenagem como instrumento de dessalinização e prevenção da salinização de solos. Revista e Ampliada. Brasília, 2.ed. CODEVASF, 2002, 216p.

CAMPOS, V. B.; CAVALCANTE, L. F.; DANTAS, T. A. G.; MOTA, J. K. M., RODRIGUES, A. C.; DINIZ, A. A. Caracterização física e química de frutos de maracujazeiro amarelo sob adubação potássica, biofertilizante e cobertura morta. Revista Brasileira de Produtos Agroindustriais, Campina Grande, v.9, n.1, p. 5971, 2007.Disponivel em: < http://www.deag.ufcg.edu.br/rbpa/rev91/Art918.pdf> Acesso em 03/nov/2016.

CHAGAS, I.M. das; TAVARES, J.C.; FREITAS, R. S. da; RODRIGUES, G.S. O. de; Formação de mudas de maracujá amarelo em quatro tamanhos de recipiente. Revista Verde de Agroecologia e Desenvolvimento Sustentável, Mossoró, v.1, n.2, p. 122-133, 2006.

EMBRAPA-Empresa Brasileira de Pesquisa Agropecuária. Clima. Disponível em:< http://www.cnpf.embrapa.br/pesquisa/efb/clima.htm>. Acesso em, 23 de março de 2016.

FAO-Organizações das Nações Unidas. Food and Agriculture Production. 2012. Disponível em: <http://faostat.fao.org/site/339/default.aspx>.

FERREIRA DF. 2010. Sistema de análise SISVAR -de variância. Versão5.3. Lavras-MG: UFLA.

FORTALEZA, J. M.; PEIXOTO, J. R., JUNQUEIRA, N. T. V.; OLIVEIRA, A. T.; RANGEL, L. E. P. Características físicas e químicas em nove genótipos de maracujá-azedo cultivado sob três níveis de adubação potássica. Revista Brasileira de Fruticultura. Jaboticabal - SP, v. 27, n. 1, p. 124-127, 2005. Disponível em: < http://www.repositorio.unb.br/bitstream/10482/6816/1/ARTIGO_Caracter\%C3\%ADsti casF\%C3\%ADsicasQu\%C3\%ADmicasNove.pdf> Acesso em: 15/dez/2016.

IBGE - Instituto Brasileiro de Geografia e Estatística. Produção Agrícola Municipal, 2013. Disponível em: http://www.ibge.gov.br/ Acesso em 5 dez. 2016.

IBGE - Instituto Brasileiro de Geografia e Estatística. Produção Agrícola Municipal, $2016 . \quad$ Disponível em: http://www.cnpmf.embrapa.br/Base_de_Dados/index_pdf/dados/brasil/maracuja/b1_ maracuja.pdf. Acesso em 21 dez. 2017.

MENEGHETTE, H. H. A.; LAZARINI, E.; BOSSOLANI, J. W.; PARRA, L.F.; HAYASHI, F. K. Doses de fósforo e potássio em plantas de amendoim na presença e ausência de adubação foliar. Brazilian Journal of Biosystems Engineering v. 11(2): 125-134, 2017. Disponível em: <DOI: http://dx.doi.org/10.18011/bioeng2017v11n2p125-134>. Acessado em 05/11/2017.

MIYAKE, R. T. M.; Nitrogênio, fósforo e potássio no estádio nutricional, produtividade e qualidade do maracujazeiro amarelo. Tese (Doutorado em AGRARIAN ACADEMY, Centro Científico Conhecer - Goiânia, v.4, n.8; p.66 
Agronomia) - Universidade do Oeste Paulista - UNOESTE, Presidente Prudente SP, $123 \quad$ f., $\quad 2016 . \quad$ Disponível em: http://bdtd.unoeste.br:8080/jspui/handle/jspui/1042>. Acesso em: 29/11/2017

MIYAKE, R. T. M.; CRESTE, J. E.; NARITA, N.; GUERRA, W. E. X. Substrato e adubação nitrogenada na produção de mudas de maracujazeiro amarelo em condições protegidas. Colloquium Agrariae, Presidente Prudente, v. 13, n.1, p. 5765 , 2017.Disponivel em: <http://revistas.unoeste.br/revistas/ojs/index.php/ca/article/view/1453/1859> DOI: 10.5747/ca.2017.v13.n1.a149. Acesso em: 27/11/2017.

SÁ, F. V. S.; BERTINO, A. M. P.; FERREIRA, N. M.; BERTINO, A. M. P.; SOARES, L. S.; MESQUITA, E. F. Formação de mudas de maracujazeiro amarelo com diferentes doses de esterco caprino e volumes do substrato. Revista Magistra, Cruz das Almas, V. 26, n. 4, p. 482-492, 2014. Disponível em: < https://magistraonline.ufrb.edu.br/index.php/magistra/article/view/483/262> Acesso em: 15/11/2016.

SANTOS, T. V.; LOPES, T. C.; SILVA, A. G.; PAULA, R. C. M.; COSTA, E.; BINOTTI, F. F. S. Produção de mudas de maracujá amarelo com diferentes materiais refletores sobre bancada. Revista de Agricultura Neotropical, Cassilândia, v. 4, n. 4, p. 26-32, 2017. Disponível em: < http://periodicosonline.uems.br/index.php/agrineo/article/view/1781>. Acesso em:15/11/2017.

Sistemas de Produção Embrapa. Disponível em: https://www.spo.cnptia.embrapa.br/conteudo?p_p_id=conteudoportlet_WAR_sistema sdeproducaolf6_1ga1ceportlet\&p_p_lifecycle $=0 \& p \_p \_s t a t e=$ normal\&p_p_mode $=v i e w$ $\& p \_p \_c o l$ id $=$ column-1\&p_p_col_count $=1 \& p \_r \_p \_-$

76293187_sistemaProducaold $=8103 \& p \_r \_p \_-996514994$ topicold $=9048$. Acesso em 21/12/2017.

WANDERLEY, R. A. Salinização de solos sob aplicação de rejeito de dessalinizadores com e sem adição de fertilizantes. Dissertação (Mestre em Engenharia Agrícola). Universidade Federal Rural de Pernambuco - UFRPE, RecifePE, $53 \quad$ f., 2009 . Disponível em: < http://www.tede2.ufrpe.br:8080/tede2/handle/tede2/5675>. Acesso em: 29/11/2017. 